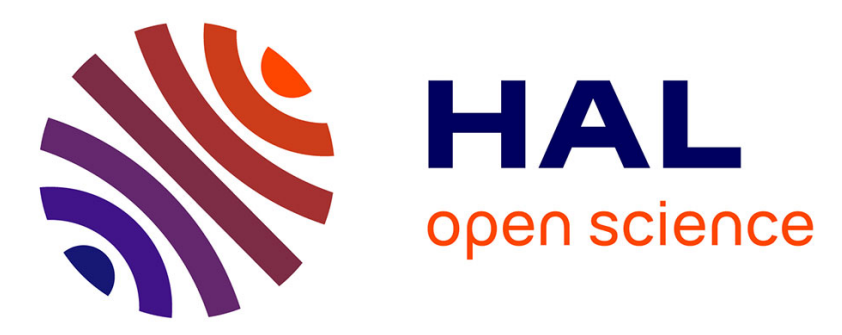

\title{
The quality factor of deeply etched quartz resonators : theory and experiments
}

T.G. Leblois, C.R. Tellier, R. Bourquin

\section{To cite this version:}

T.G. Leblois, C.R. Tellier, R. Bourquin. The quality factor of deeply etched quartz resonators: theory and experiments. Revue de Physique Appliquée, 1989, 24 (9), pp.877-892. 10.1051/rphysap:01989002409087700 . jpa-00246111

\section{HAL Id: jpa-00246111 https://hal.science/jpa-00246111}

Submitted on 1 Jan 1989

HAL is a multi-disciplinary open access archive for the deposit and dissemination of scientific research documents, whether they are published or not. The documents may come from teaching and research institutions in France or abroad, or from public or private research centers.
L'archive ouverte pluridisciplinaire $\mathbf{H A L}$, est destinée au dépôt et à la diffusion de documents scientifiques de niveau recherche, publiés ou non, émanant des établissements d'enseignement et de recherche français ou étrangers, des laboratoires publics ou privés. 
Classification

Physics Abstracts

$61.70 \mathrm{~J}-62.30-68.90-77.90$

\title{
The quality factor of deeply etched quartz resonators : theory and experiments
}

\author{
T. G. Leblois, C. R. Tellier and R. Bourquin
}

Laboratoire de Chronométrie, Electronique et Piézoélectricité, Ecole Nationale Supérieure de mécanique et de Microtechniques, route de Gray, La Bouloie, 25030 Besançon Cedex, France

(Reçu le 7 mars 1989, révisé le 29 mai 1989, accepté le 30 mai 1989)

\begin{abstract}
Résumé. - Nous avons développé un modèle théorique qui décrit l'influence des états géométriques de surface sur le coefficient de qualité de résonateurs à quartz. Dans ce modèle la surface des résonateurs usinés chimiquement est représentée par une succession de facettes triangulaires planes d'orientation diverses. Le coefficient de réflexion d'une onde diffractée par une facette d'orientation donnée est calculé en prenant en compte l'anisotropie du milieu de propagation. L'atténuation supplémentaire que subissent les ondes acoustiques après réflexion sur les surfaces rugueuses du résonateur est alors fonction du critère de rugosité $R_{\mathrm{q}}$ et de la taille moyenne des facettes. Une étude expérimentale de l'évolution des états géométriques de surface et des variations du coefficient de qualité $Q_{\mathrm{F}}^{*}$, avec la profondeur d'attaque $\Delta d_{\mathrm{s}}$ de lames de quartz d'orientation $\theta=-49^{\circ}$ a été entreprise. Elle a montré que l'évolution du coefficient est corrélée aux divers états géométriques successifs qui se développent sur des surfaces de quartz usinées chimiquement. Une comparaison des courbes théoriques $\left(Q_{\mathrm{F}}^{*}, \Delta d_{\mathrm{s}}\right)$ avec les courbes expérimentales a révélé un bon accord entre la théorie et l'expérience dès que la taille des figures de dissolution n'est pas trop petite devant la longueur d'onde.
\end{abstract}

\begin{abstract}
A theoretical model which describes the influence of the surface topography, on the quality factor of quartz resonators is proposed. In this model the surface of chemically etched resonators is represented by a succession of triangular flat faces with varying orientation. Then the reflexion coefficient related to an incoming wave scattered at a given face is calculated by taking into account the anisotropy of the propagating medium. The additional attenuation caused by the scattering at the resonator rough surfaces is found to be expressed in terms of the r.m.s. roughness and the average sizes of triangular faces. Experimental results on the changes of the surface topography and on the variations of the quality factor, $Q_{\mathrm{F}}^{*}$, with the depth of etch, $\Delta d_{\mathrm{s}}$, of BT-49 quartz plates are presented. The evolution of the quality factor is found to be closely correlated with changes in the geometrical features of resonator surfaces. The comparison of the theoretical $Q_{\mathrm{F}}^{*}$ vs. $\Delta d_{\mathrm{s}}$ plot with the experimental one shows a complete agreement as soon as the sizes of the triangular face are not too small compared with the wavelength of the acoustical wave.
\end{abstract}

\section{Introduction.}

Quartz resonators plates are generally prepared by mechanical processes such as lapping and polishing [1]. Mechanical lapping results in the formation of a disturbed surface layer [2-8] which can markedly affect the performance of the resonator [4-9]. Hence in the past few years some measurements [7-9] have been made to evaluate the influence of this disturbed surface layer on the quality factor, $Q$, of quartz resonators. But to our knowledge there is up to now no theoretical model devoted to the description of the effect of geometrical imperfections of the re- sonator surfaces on the $Q$-factor, except the model proposed by Castellano et al. [8] which is essentially concerned with changes in the $Q$-factor caused by the presence of a disturbed surface layer.

In the paper we present a model for the dependence of the $Q$-factor of quartz resonators on the crystal surface textures in absence of a disturbed surface layer. In order to discuss the validity of the model it is necessary to undertake a systematic comparison of the theoretical predictions with the experimental results on various surface texture. For this purpose chemically etched quartz resonators 
were used. Effectively, previous studies [10-13] on the chemical etching of differently oriented quartz plates have revealed that on the one hand, the shape of the dissolution figures which develop on quartz surfaces depends on the crystal orientation and on the other hand the etch figures enlarge with prolonged etching. It thus appears that chemical etching enables to produce various surface textures which can be described by rapidly varying statistical parameters. Moreover as soon as a critical depth of etch of about $1-2 \mu \mathrm{m}$ is removed from singly-rotated quartz plates, the chemical etching produces surfaces of various geometrical aspects for which we can roughly assume that the crystal lattice remains undisturbed even at small distances of the real surface $[10,11]$. Thus chemical etching constitutes the more convenient way to prepare quartz surfaces with various textures whose effect on the $Q$-factor can be analysed in the framework of the present model.

\section{Mathematical model.}

2.1 PhysicAl BASIS. - Here we are concerned with quartz resonator plates (diameter $\varnothing=18 \mathrm{~mm}$, thickness $d_{0} \simeq 1 \mathrm{~mm}$ ) vibrating in thickness-shear mode. Hence the resonator is identified with a flat plate of infinite dimensions and its quality factor, $Q$, can be calculated by considering the attenuation of a bulk acoustical plane wave propagating from one face of the resonator to the other one along the thickness direction, $x_{2}$, of the resonator. When the two faces are perfectly flat and smooth the attenuation is only due to the viscosity, $\eta$, of the quartz material [14]. As the quartz surfaces become rougher the plane acoustical wave is partly diffracted by the geometrical irregularities and as a result the wave scattered by the rough surfaces can be decomposed into a coherent plane wave and into an incoherent diffracted wave [15]. The incoherent wave does not longer take part to the resonance and, in reality, is dissipated within the bulk crystal contributing to the attenuation. The coherent part of the scattered wave is calculated by means of the Kirchhoff's diffraction theory [16] in an isotropic medium. This constitutes an oversimplification but as the quartz crystal is a very slightly anisotropic material we expect this approximation to be still valid. However the calculation of the reflection coefficient for the incoming wave is performed taking into account the anisotropy of the quartz crystal. Here it should be pointed out that profilometry traces made along various directions of differently oriented etched surfaces have given evidence [10-12] that surface elements make a small angle with respect to a reference surface $\left(x_{1}, x_{3}\right)$ perpendicular to the incoming mechanical wave. Thus multiple scatterings of wave and the geometrical shadowing of the surface by itself [17, 18] can be neglected.

The problem is now : how to describe the rough etched quartz surfaces? Let us recall that previous experiments on the etching of differently oriented quartz plates [11-13] have shown that the typical dissolution figures which are formed on the quartz surface can be roughly decomposed in several flat faces whose orientation and spatial distribution vary with the crystal orientation. In particular for the crystal orientations investigated here the fondamental dissolution figure can be crudely assimilated to a single elongated triangular face [11]. Hence in this paper we assume that the etched surface can be described by a succession of triangular faces, perfectly flat, whose dimensions in the reference plane can be considered as statistically constant and whose distribution of heights is supposed to exhibit a Gaussian form. In this study two vertical descriptors [19] are used to characterize the etched surface namely the root-mean-square roughness, $R_{\mathrm{q}}$, which in terms of the height distribution can be identified with the standard deviation, $\sigma$, and the maximum peak-to-valley height $R_{\max }$. The spatial arrangement of the surface is seen through two geometrical parameters, $a$ and $b$, which correspond to the length of a triangular face along the $x_{1}$ and $x_{3}$ axes respectively. The geometry of the triangular face corresponding to the fondamental dissolution figure is illustrated in figure 1 . The origin, $\mathrm{O}$, of coordinates is taken in the mean reference plane $\left(x_{1}, x_{3}\right)$. The distances related to the geometrical parameters, $a, b, h$ and $h^{\prime}$ are small in comparison with the size of the resonator. Moreover as noticed above the triangular faces are weakly disoriented with respect to the reference plane $\left(x_{1}, x_{3}\right)$. This may be written as $h^{\prime}<a$ and $h<b$.

The incoming plane wave, $\mathbf{u}^{1}$, of wave vector $\mathbf{k}^{1}$ propagates in the direction $-\mathbf{x}_{2}$. In the framework of the Kirchhoff's theory the coherent part, $u_{\text {coh }}$, of the total wave diffracted by an infinity of triangular faces is given by $[20,21]$

$$
\begin{aligned}
& u_{\mathrm{coh}}=\iiint_{-R_{\max } / 2}^{R_{\max } / 2} u(M) R^{x}\left(\ell_{1}, \ell_{3}\right) \times \\
& \times P\left(x_{2}\right) P\left(x_{2}+h\right) P\left(x_{2}+h+h^{\prime}\right) \mathrm{d} x_{2} \mathrm{~d} h \mathrm{~d} h^{\prime} .
\end{aligned}
$$

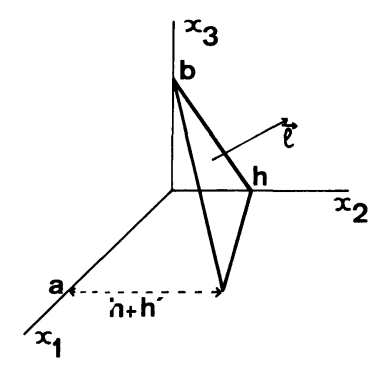

Fig. 1. - The geometry of a triangular face. 
In this equation $P\left(x_{2}\right)$ is the probability of finding a surface height deviation $x_{2}$, chosen to be gaussian

$$
P\left(x_{2}\right)=\left(2 \pi \sigma^{2}\right)^{-1 / 2} \exp \left(-x_{2}^{2} / 2 \sigma^{2}\right)
$$

and $R^{x}\left(\ell_{1}, \ell_{3}\right)$ is the reflection coefficient when the incoming plane wave is scattered by a flat plane whose orientation coincides with that of the triangular face with outward normal $\ell\left(\ell_{1}, \ell_{2}, \ell_{3}\right)$. The term $u(M)$ represents the amplitude of the diffracted wave at a point $M$ lying at an infinite distance from the scattering triangular face. To calculate $u(M)$ we follow the mathematical treatment involved in the Kirchhoff's theory. At a point of observation, $M$ located at $x_{2} \rightarrow \infty, u(M)$ is given by

$$
\begin{aligned}
u(M)=-\frac{i u^{1}}{2 \lambda} \iint_{\mathcal{A}} \frac{1}{s} & \left\{\cos (\ell, \mathbf{s})-\cos \left(\mathbf{k}^{\mathrm{R}}, \ell\right)\right\} \times \\
& \times \exp \left\{i\left(k_{\mathrm{s}}^{\mathrm{R}}+\mathbf{k}^{1} \cdot \mathbf{r}\right)\right\} \mathrm{d} \mathcal{A}
\end{aligned}
$$

where the superscripts $\mathrm{R}$ and 1 refer to the scattered and incoming waves respectively. $s$ is the distance between the point $\mathrm{M}$ and a particular point $Q$ of the triangular face of area $\mathcal{A} . \ell$ is the unit outward normal to the triangular face and $\mathbf{r}=\mathbf{O Q}$. It should be remarked that since we are concerned with mechanical displacements the incoming wave is a plane wave so that the term $\mathbf{k}^{1} \cdot \mathbf{r}$ is involved in the expression of $u(M)$.

In the particular case where the point $M$ is located at an infinite distance from the triangular face, we can expand the distance $s$ in ascending powers with respect to $h / b$ and $h^{\prime} / a$. As the distances $h$ and $h^{\prime}$ are small compared with the respective distances $b$ and $a$ we can neglect, in a second step, terms of order higher than four. Hence, equation (3) reduces to

$$
\begin{aligned}
u(M)= & \frac{A \ell_{2} \exp \left\{i k\left(s^{\prime}+h-h^{\prime}\right)\right\}}{4 \pi h s^{\prime}} \times \\
& \times\left\{\mathrm{e}^{-i k h} \frac{\sin k h^{\prime}}{k h^{\prime}}-\frac{\sin \left(k\left(h+h^{\prime}\right)\right)}{k\left(h+h^{\prime}\right)}\right\}
\end{aligned}
$$

where $s^{\prime}$ is the distance between the point $\mathrm{M}$ and the origin, $\mathrm{O}$, of the coordinates, and $A$ is the amplitude of the incident wave.

Into equation (4) the component $\ell_{2}$ of the normal $\ell$ is connected with the geometrical parameters $h, h^{\prime}$, $a$ and $b$ by means of equation (5)

$$
\begin{aligned}
\ell_{2}=1-\frac{1}{2}\left\{\frac{h^{\prime 2}}{a^{2}}+\frac{h^{2}}{b^{2}}\right\} & - \\
& -\frac{1}{8}\left\{\frac{h^{\prime 4}}{a^{4}}+\frac{h^{4}}{b^{4}}+2 \frac{h^{\prime 2} h^{2}}{a^{2} b^{2}}\right\} .
\end{aligned}
$$

2.2 The REFLECTION COEFFICIENT. - We now proceed to calculate the reflection coefficient $R^{x}\left(\ell_{1}, \ell_{3}\right)$ for an anisotropic medium. To begin with, let us recall that for an anisotropic crystal the reflection coefficient related to an incoming wave associated with a mechanical displacement, $u^{1}$, is derived [20-22] assuming that the boundary condition of zero stress at the free mean plane is satisfied

$$
\sum_{x=L, T_{1}, T_{2}} C_{i j k \ell} \ell_{j} k_{\ell}^{x} u_{k}^{x}+C_{i j k 2} \ell_{j} k_{2}^{1} u_{k}^{1}=0
$$

where the $C_{i j k \ell}$ are the second order elastic stiffness of quartz while $x$ denotes one of the three possible modes for the scattered wave, namely the longitudinal mode $(\mathrm{L})$, or a transverse mode $\left(\mathrm{T}_{1}, \mathrm{~T}_{2}\right)$.

The wave vector $\mathbf{k}^{x}=\left(\omega / v^{x}\right) \mathbf{n}^{x}$ and the mechanical displacement field $\mathbf{u}^{x}$ related to the three scattered waves are derived starting from the Christoffel's equation [22]

$$
C_{i j k \ell} n_{j}^{x} n_{\ell}^{x} u_{k}^{x}-\rho v^{x^{2}} u_{i}^{x}=0
$$

where $n_{j}^{x}, u_{i}^{x}$ and $v^{x}$ are functions of the cartesian components of the normal $\ell$ at the scattering surface.

For the purpose of solving the Christoffel's equation it is usual [22] to introduce the tensor of rank two :

$$
\Gamma_{i k}=C_{i j k \ell} n_{j} n_{\ell}
$$

the eigenvalues, $\rho v_{R}^{2}$, are then determined taking the determinant $\mathfrak{D}$ as zero :

$$
\mathscr{D}=\left|\Gamma_{i k}-\rho v_{\mathrm{R}}^{2} \delta_{i k}\right|=0
$$

where $\rho$ is the mass density.

To deal with equation (9) we need to manipulate the components $\Gamma_{i j}$ which are given as functions of the cosine directions, $n_{i}^{x}$, related to the scattering direction $[20,22]$

$$
\begin{gathered}
n_{1}^{x}=-\frac{v_{\mathrm{R}}^{x}}{v_{1}} \ell_{1}\left[\ell_{2}+\left[\ell_{2}^{2}-1+\frac{v_{1}^{2}}{V_{\mathrm{R}}^{x^{2}}}\right]^{1 / 2}\right] \\
n_{2}^{x}=\frac{v_{\mathrm{R}}^{x}}{v_{1}}-\frac{v_{\mathrm{R}}^{x}}{v_{1}} \ell_{2}\left\{\ell_{2}+\left(\ell_{2}^{2}-1+\frac{v_{1}^{2}}{v_{\mathrm{R}}^{x^{2}}}\right)^{1 / 2}\right\} \\
n_{3}^{x}=-\frac{v_{\mathrm{R}}^{x}}{v_{1}} \ell_{3}\left\{\ell_{2}+\left(\ell_{2}^{2}-1+\frac{v_{1}^{2}}{v_{\mathrm{R}}^{x^{2}}}\right)^{1 / 2}\right\} .
\end{gathered}
$$

For the further solutions of equation (9) it is convenient to define the term $A^{x}$

$$
A^{x}=\ell_{2}+\left(\ell_{2}^{2}-1+v_{1}^{2} / v_{\mathrm{R}}^{x^{2}}\right)^{1 / 2}
$$

so that the expression of the determinant $\mathscr{D}$ becomes a (somewhat complicated) function of the 6th order in $A^{x}$. Thus setting $\mathfrak{D}=0$ and solving by numerical method this equation for a given set of $\left(\ell_{1}\right.$, $\ell_{2}, \ell_{3}$ ) gives only three physical consistent values for $A^{x}$ and consequently, three solutions for the eigen- 
values. If we further substitute these eigenvalues in the Christoffel equation we finally obtain the eigenvectors $u^{x}$.

We now wish to turn to the reflection coefficient $R^{x}$ which from the general definition of a reflection coefficient can be written in the form :

$$
R^{x}=\left(u_{1}^{x^{2}}+u_{2}^{x^{2}}+u_{3}^{x^{2}}\right)^{1 / 2} / u^{1} .
$$

Thus this procedure allows us to evaluate numerically the reflection coefficient related to a face of given orientation $\left(\ell_{1}, \ell_{2}, \ell_{3}\right)$. However, integration of equation (1) requires to know $R^{x}$ for any given orientation. In order to proceed easily with the integration of equation (1) we need now to deal with some approximate expression for the reflection coefficient. Previous studies [20, 21] have given evidence that an analytical expression for $R^{x}$ results from a serie's expansion of $R$ with respect to $\ell_{j}$ where only terms up to the second order in $\ell_{j}$ are retained. Following this procedure again but retaining here up to the 4 th-order terms yields

$$
\begin{aligned}
R & =1+\alpha_{1} \ell_{1}+\alpha_{2} \ell_{3}+\alpha_{3} \ell_{1}^{2}+\alpha_{4} \ell_{3}^{2}+\alpha_{5} \ell_{1} \ell_{3} \\
& +\alpha_{6} \ell_{1}^{3}+\alpha_{7} \ell_{3}^{3}+\alpha_{8} \ell_{1}^{2} \ell_{3}+\alpha_{9} \ell_{1} \ell_{3}^{2}+\alpha_{10} \ell_{1}^{4} \\
& +\alpha_{11} \ell_{3}^{4}+\alpha_{12} \ell_{1}^{3} \ell_{3}+\alpha_{13} \ell_{1} \ell_{3}^{3}+\alpha_{14} \ell_{1}^{2} \ell_{3}^{2} .
\end{aligned}
$$

Thus it appears that to evaluate numerically the coefficients $\alpha_{i}$ it becomes necessary to repeat the preceding procedure for fourteen different sets $\left(\ell_{1}, \ell_{2}, \ell_{3}\right)$. As an example, table I illustrates the final result of the numerical treatment in the particular case where the mean reference surface corresponds to a singly-rotated quartz plate with $\theta=-49^{\circ}$.

Table I. - Theoretical values of the coefficient $\alpha_{i}$ as deduced from the numerical treatment.

\begin{tabular}{|c|l|c|c|l|l|r|r|r|l|l|l|l|r|r|}
\hline$i$ & 1 & 2 & 3 & 4 & 5 & 6 & 7 & 8 & 9 & 10 & 11 & 12 & 13 & 14 \\
\hline$\alpha_{i}$ & 0.024 & -0.012 & -23.34 & 0.067 & 1.248 & -19.7 & 0.96 & 0.555 & 21.05 & 660.7 & -55.2 & -272.7 & -149.9 & 1459 \\
\hline
\end{tabular}

2.3 THE QUALITY FACTOR OF THE RESONATOR. For a plane wave travelling along the normal to a perfectly flat plate the equation of propagation is given by [22]

$$
\rho \omega^{2} u_{i}=C_{i 22 \ell} \frac{\partial^{2} u_{\ell}}{\partial x_{2}^{2}}+i \eta_{i 22 \ell} \frac{\partial^{2} u_{\ell}}{\partial x_{2}^{2}} \omega .
$$

We can now apply the usual procedure [22] which consists of transforming the tensors to principal axes to obtain the equation

$$
\left(C^{x}+i \eta^{x} \omega\right) \frac{\partial^{2} u^{x}}{\partial x_{2}^{2}}=\rho \omega^{2} u^{x}
$$

where $C^{x}$ and $\eta^{x}$ denote the new stiffness and viscosity coefficients related to a particular mode $x$ [14].

Thus according to equation (17) we can associate the complex wave number

$$
k=k+i \mathcal{R}=\omega\left(\rho / C^{x}\right)^{1 / 2}\left(1+i \omega\left(\eta^{x} / 2 C^{x}\right)\right)
$$

with the plane wave propagating along $x_{2}$.

We now proceed to calculate the total attenuation $A_{\mathrm{t}}$ due on the one hand to the viscosity and on the other hand to the scattering by rough surfaces. For a resonator with perfectly smooth and flat surfaces the plane wave travelling along a distance $2 d_{0}$ (the thickness of the resonator) suffers an attenuation $A_{0}$ given by $[19,20]$

$$
A_{0}=\mathrm{e}^{-2 R d_{0}} \text {. }
$$

For the rough surfaces under consideration integrating equation (1) over the range $-R_{\max } / 2$, $R_{\max } / 2$ with respect to the variables $x_{2}, h$ and $h^{\prime}$ yields :

$$
\begin{aligned}
& u_{\mathrm{coh}}(\sigma)=\left\{\left[1+\sigma^{2}\left(\frac{2 \alpha_{3}-1}{a^{2}}+\frac{2 \alpha_{4}-1}{b^{2}}-\frac{\alpha_{5}}{a b}-k^{2}\right)\left(1-a^{\prime} A_{\mathrm{erf}}\right)+\sigma^{4}\left\{\left(\left(2 \alpha_{10}-3 \alpha_{3}+\frac{3}{4}\right) \frac{1}{a^{4}}+\right.\right.\right.\right. \\
& \left.+\left(2 \alpha_{11}-3 \alpha_{4}+\frac{3}{4}\right) \frac{1}{b^{4}}-\left(\frac{\alpha_{5}}{2}+\alpha_{12}\right) \frac{1}{a^{3} b}-\left(\frac{\alpha_{5}}{2}+\alpha_{13}\right) \frac{1}{a b^{3}}+\left(\alpha_{14}-\alpha_{3}-\frac{3 \alpha_{4}}{2}-\frac{1}{4}\right) \frac{1}{a^{2} b^{2}}\right) \\
& \times\left[3\left(1-a^{\prime} A_{\mathrm{erf}}\right)^{2}+\left(3-6 a^{\prime} A_{\mathrm{erf}}-4 a^{\prime 3} A_{\mathrm{erf}}\right)\right]+\frac{k^{2}}{3}\left(\frac{1-2 \alpha_{4}}{b^{2}}+\frac{1-2 \alpha_{3}}{a^{2}}+\frac{\alpha_{5}}{a b}\right) \\
& \times\left[\left(1-A_{\mathrm{erf}}\right)^{2}+3-6 a^{\prime} A_{\mathrm{erf}}-4 a^{\prime 3} A_{\mathrm{erf}}\right] \\
& \left.\left.\left.+\frac{2 k^{4}}{15}\left(3-6 a^{\prime} A_{\mathrm{erf}}-4 a^{\prime 3} A_{\mathrm{erf}}-4\left(1-a^{\prime} A_{\mathrm{erf}}\right)^{2}\right)\right\}\right]^{2}+16 \sigma^{8} k^{6}\left(\frac{\alpha_{1}}{a}-\frac{\alpha_{2}}{b}\right)^{2}\left(1-a^{\prime} A_{\mathrm{erf}}\right)^{4}\right\}^{1 / 2} \operatorname{erf}^{3}\left(a^{\prime}\right)
\end{aligned}
$$


with

$$
a^{\prime}=R_{\max }\left[2^{3 / 2} \sigma\right]^{-1}
$$

and

$$
A_{\text {erf }}=\exp \left(-a^{\prime 2}\right) \cdot \operatorname{erf}^{-1}\left(a^{\prime}\right)
$$

where erf is the error function.

The additional attenuation $A_{\mathrm{r}}$ caused by the scattering at rough surface is given by

$$
A_{\mathrm{r}}=\frac{u_{\mathrm{coh}}(\sigma)}{u_{\mathrm{coh}}(\sigma=0)} .
$$

Thus during a travel of length $2 d_{0}$, the total attenuation, $A_{\mathrm{t}}$, can be rewritten as

$$
A_{\mathrm{t}}=\exp \left\{-k^{x} \cdot \frac{\eta^{x^{*}} \omega}{C^{x}} d_{0}\right\}
$$

where the effect of the rough surface is seen through the effective viscosity constant $\eta^{x^{*}}$.

Turning now our attention to the quality factor of a resonator which is given by the relation

$$
Q=C^{x}\left[\eta^{x^{*}} \omega\right]^{-1}
$$

and then combining equations (23) and (24) to extract $\eta^{x^{*}}$, we obtain the quality factor of the etched resonator as

$$
Q^{-1}=Q_{0}^{-1}-\frac{2}{\pi N_{p}} \ln \left(A_{\mathrm{r}}\right)
$$

where $N_{\mathrm{p}}=3$ for our 3 th overtone quartz resonators.

In equation (26) $Q_{0}$ is the quality factor of a resonator whose free surfaces are perfectly flat and smooth.

\section{Experimental results.}

3.1 EXPERIMENTAL PROCEDURE. - The resonators used are $5 \mathrm{MHz}$ third overtone planoconvex quartz plates. The singly rotated quartz plates with the angle $\theta$ respectively equal to $-49^{\circ}$ and $-41^{\circ}$ and labelled for convenience BT-49 and BT-41 were cut from similar synthetic quartz crystals. Before etching the plates were lapped with a $5 \mu \mathrm{m}$ abrasive. The solvant used was ammonium bifluoride (typical concentration $C=10.5 \mathrm{~mol} \mathrm{l}^{-1}$ ) which is known to be a good solvant for quartz [23]. The plates were etched at a constant temperature of $330 \mathrm{~K}$ for successive periods of time in such a way that after the first stages of etching a depth of etch, $\Delta d_{s}$, of about $1 \mu \mathrm{m}$ was reached. Further to obtain large changes in the peak-to-valley height on etching the etching time was modified to give a depth of etch of $8 \pm 3 \mu \mathrm{m}$ by stage.

The topography of the etched surfaces of the quartz plates was studied by means of two different

REVUE DE PHYSIQUE APPLIQUÉE. - T. 24, N` 9, SEPTEMBRE 1989 procedures. Firstly, profilometry traces were made at any time of etching along eight different directions of the two surfaces of the resonators in order to determine average values of the vertical roughness parameters $R_{\max }$ and $R_{\mathrm{q}}$. Moreover the characterization of the surface texture was achieved using a microcomputer and a program [24] which enables to extract the distribution of heights. Secondly the etched plates were examined by scanning electron microscopy (SEM) after each isothermal etching. The SEM micrographs were taken along an observation angle of $0^{\circ}$. They give average values of the parameters $a$ and $b$.

Measurements of the $Q$-factor of the various BT49 and BT-41 plates were performed at room temperature in high vacuum $\left(\simeq 10^{-6}\right.$ Torr $)$. The electrodeless resonators we mounted between two brass electrodes in such a way that an air gap of about $5-10 \mu \mathrm{m}$ was formed. After each stage of etching data for at least ten resonators were needed to avoid uncertainties in the measurement of the $Q$ factor. The resulting inaccuracy in the $Q$-factor was estimated to be $5 \%$ in the electrodeless configuration.

3.2 EXPERIMENTAL RESULTS. - Since the various BT-49 plates behave in the same way we restrict here the discussion of topography data to a single BT-49 plate.

The influence of the depth of etch, $\Delta d_{s}$, on the shape of profilometry traces made along the $Z^{\prime}$ direction of etched BT-49 plates is illustrated in figures 2 and 3.

3.2.1 Moderate etchings of the BT-49 surfaces (Fig. 2) lead to the formation of dissolution profiles uniformly shaped and characteristic of the crystal orientation. It may be seen from figure 4 which gives magnifications of $Z^{\prime}$ profilometry traces at different etching times that a convex section, which shows planes whose orientations remain unaffected with repeated etchings, develops progressively. Moreover prolonged etching causes an increase of both the maximum peak-to-valley height and the waviness spacing. The corresponding height distributions are displayed in figure 5. Despite of a slight asymmetric spread of the negatively skewed height distributions, the assumption of Gaussian height distribution is reasonable. Moreover when the etch depths vary from $2 \mu \mathrm{m}$ to $12 \mu \mathrm{m}$, slight changes of the average roughness $R_{\mathrm{q}}$ from about $0.2 \mu \mathrm{m}$ to $0.3 \mu \mathrm{m}$ are observed.

SEM micrographs (Fig. 6) of the BT-49 cut plates reveal additional features. As soon as a critical depth of etch of about $2 \mu \mathrm{m}$ is reached, the BT-49 surfaces are covered by typical and uniformly shaped etch figures with a marked elongation along the crystallographic $X$ direction. On more deeply etched BT-49 

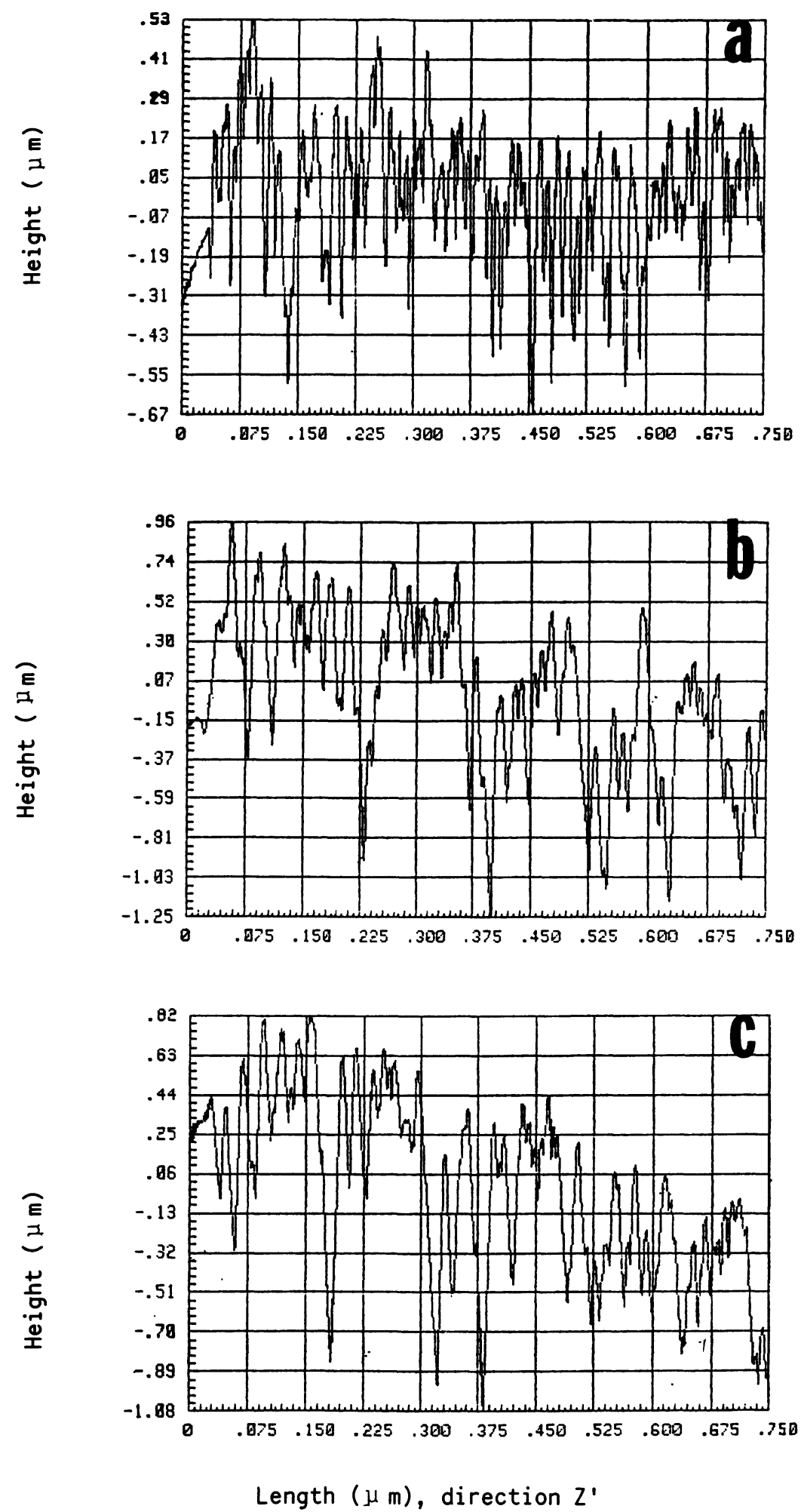

Fig. 2. - The changes in shape of the $Z^{\prime}$ profilometry traces with the depth of etch, $\Delta d_{s}$, in the first stages of etching : a) $\Delta d_{\mathrm{s}}=1.6 \mu \mathrm{m}$; b) $\Delta d_{\mathrm{s}} \simeq 4.4 \mu \mathrm{m}$; c) $\Delta d_{\mathrm{s}} \simeq 8.2 \mu \mathrm{m}$.

plates $\left(\Delta d_{\mathrm{s}}>7 \mu \mathrm{m}\right)$ a ridged background structure elongated along the $X$ direction develops. Then the spatial arrangement of the triangular dissolution figures is characterized by a marked increase in the geometrical parameter a with prolonged etching.
3.2.2. Deep etching corresponding to depths of etch in the range $(17 \mu \mathrm{m}-42 \mu \mathrm{m})$ reveals larger and deeper etch pits (Fig. 3).

These pits of different morphology are composed of facets with sharp edges showing a great contrast 

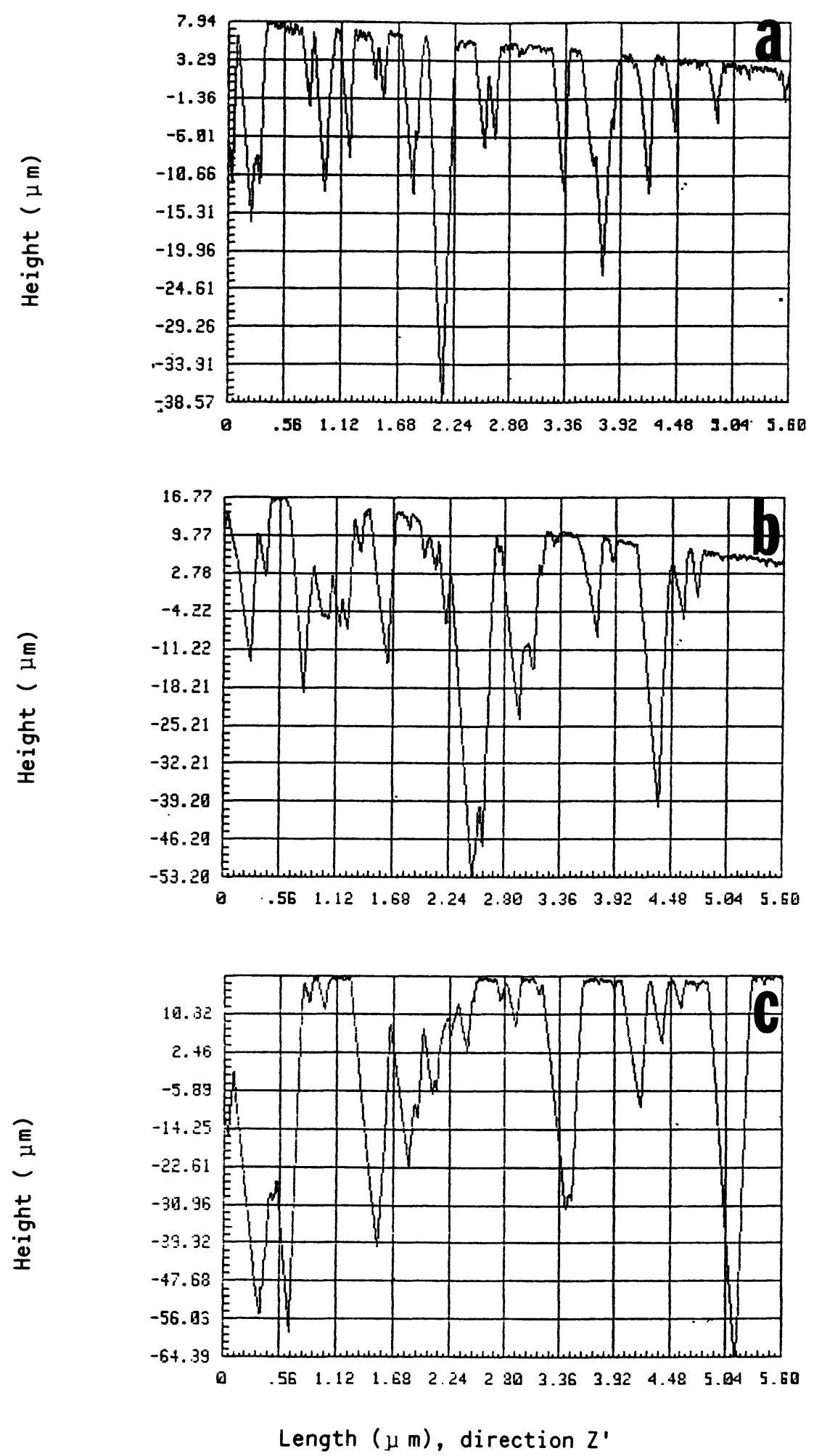

Fig. 3. - The changes in shape of the $Z^{\prime}$ profilometry traces with the depth of etch, $\Delta d_{\mathrm{s}}$, in the last stages of etching : a) $\Delta d_{\mathrm{s}} \simeq 25 \mu \mathrm{m}$; b) $\Delta d_{\mathrm{s}} \simeq 35 \mu \mathrm{m}$; c) $\Delta d_{\mathrm{s}} \simeq 41 \mu \mathrm{m}$.

(Fig. 7). They are probably $[25,26]$ associated with dislocations emerging on the BT-49 surfaces and thus are called dislocation etch pits in the following. The density of dislocation etch pits increases rapidly with repeated etchings (Fig. 8) and as a result, the dislocation etch pits tend to mask the dissolution figures whose formation is caused by orientation effect [25, 29] exclusively.

The $Z^{\prime}$ profilometry traces of figure 3 show that repeated etchings give rise to deeper and deeper 

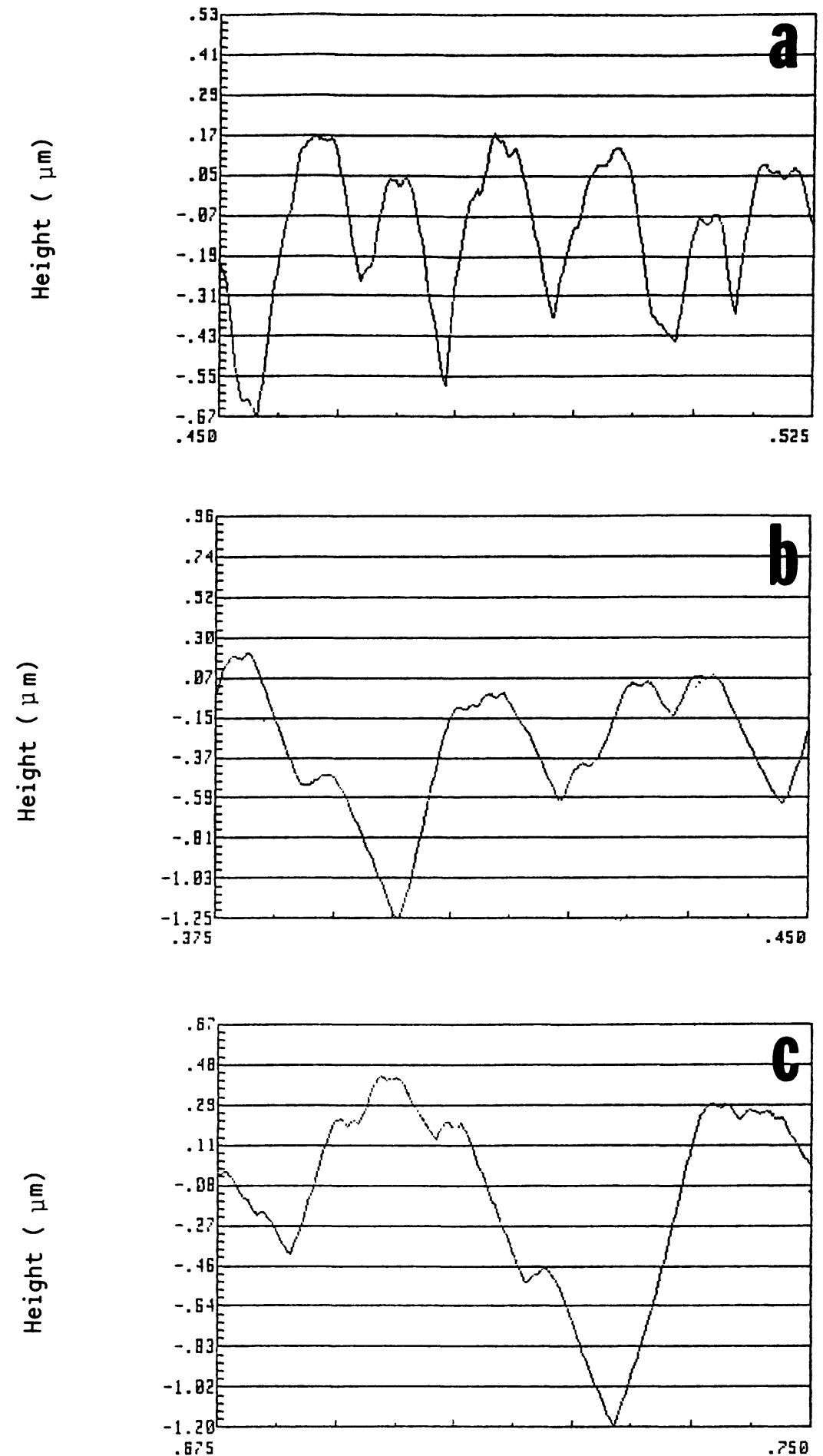

Length $(\mu \mathrm{m})$, direction $Z^{\prime}$

Fig. 4. - Magnifications of the $Z^{\prime}$ profilometry traces : a) $\Delta d_{\mathrm{s}}=1.6 \mu \mathrm{m}$; b) $\Delta d_{\mathrm{s}} \simeq 4.4 \mu \mathrm{m}$; c) $\Delta d_{\mathrm{s}} \simeq 8.2 \mu \mathrm{m}$.

dislocation etch pits leading to large increases in the $R_{\mathrm{q}}$ and the $R_{\max }$ values. The width, $b$, of dislocation etch pits also becomes larger and larger with the etching time. Thus we can assume that the density of dislocation etch pits, i.e. the area, $s_{\mathrm{E}}$, of the BT-49 surface covered by these pits, determines the performance of resonators.

Moreover profilometry traces of figure 3 allow to classify the dislocation etch pits into different categories depending on their depths, i.e. on the 

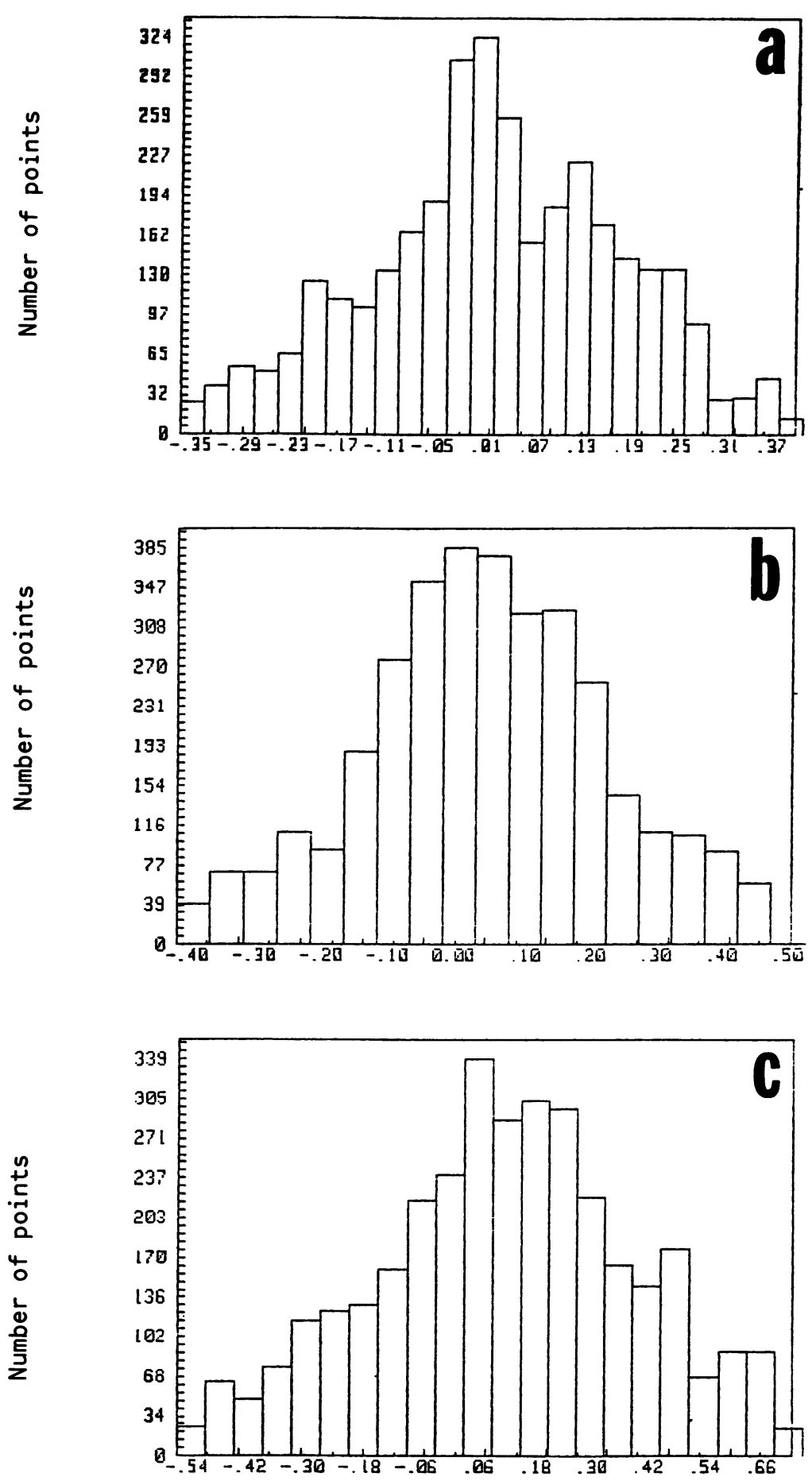

Height $(\mu \mathrm{m})$, direction $Z^{\prime}$

Fig. 5. - Evolution of the distribution of heights with the depth of etch $\Delta d_{\mathrm{s}}$ : a) $\Delta d_{\mathrm{s}} \simeq 1.6 \mu \mathrm{m}$; b) $\Delta d_{\mathrm{s}} \simeq 4.4 \mu \mathrm{m}$; c) $\Delta d_{\mathrm{s}} \simeq 8.2 \mu \mathrm{m}$.

maximum peak-to-valley height. In addition, simultaneous examination of $Z^{\prime}$ profilometry and SEM micrographs allow us to determine the average values of the geometrical parameters $a$ and $b$ associated with each category of etch pits.

Apart these geometrical features of etch pits it seems of interest to collect some informations on the height distributions of deeply etched BT-49 surfaces. The height distributions of deeply etched BT-49 surfaces reported on figure 9 are still nearly Gaussian.

Experimental results on the $Q$-factor, obtained from a great number of resonators are plotted in figure 10 as a function of the etch depth for several 

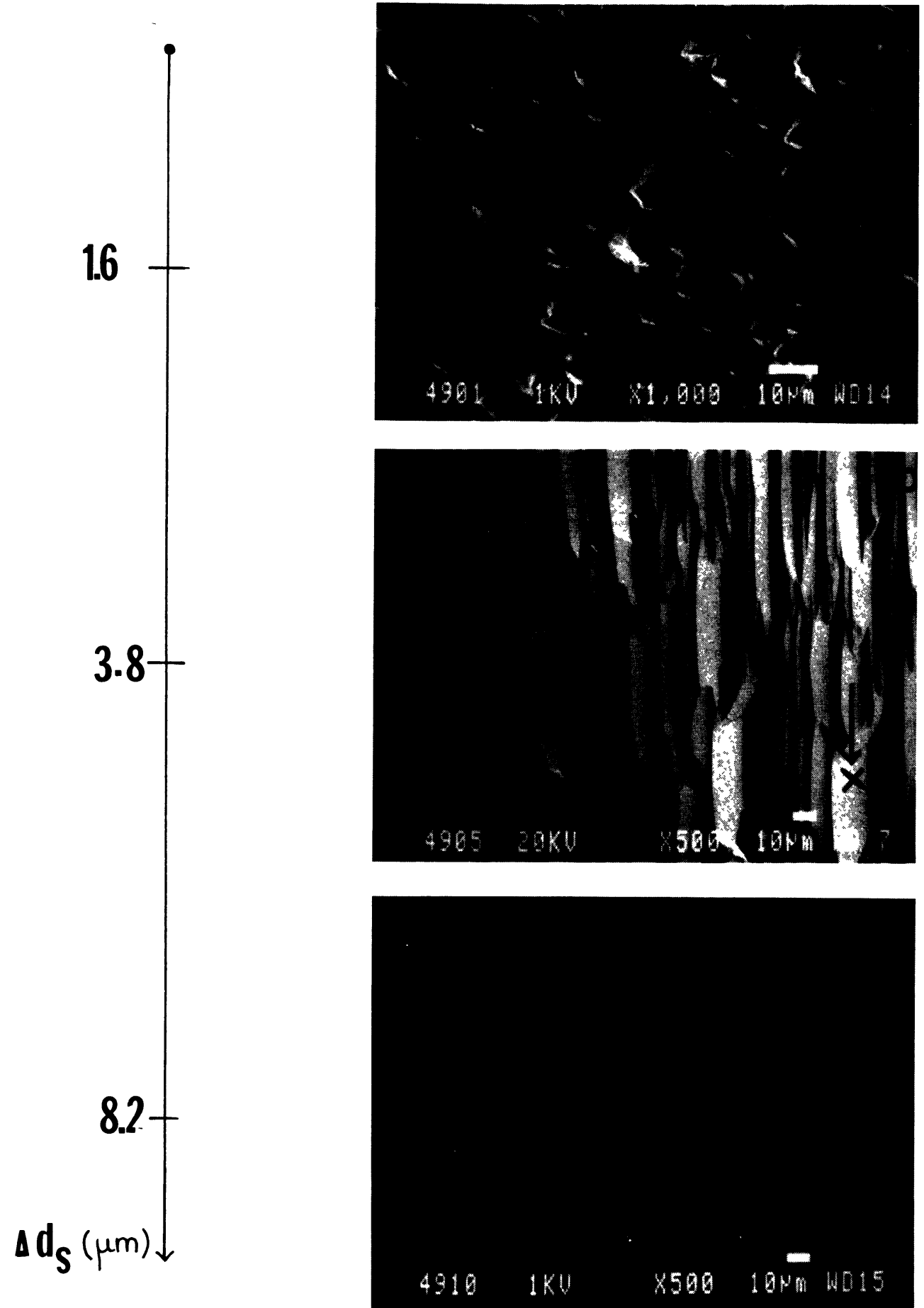

Fig. 6. - SEM micrographs of moderately etched BT-49 plates: a) $\Delta d_{\mathrm{s}} \simeq 1.8 \mu \mathrm{m} ;$ b) $\Delta d_{\mathrm{s}} \simeq 3.8 \mu \mathrm{m}$; c) $\Delta d_{\mathrm{s}} \simeq 8.2 \mu \mathrm{m}$.

BT-49 quartz plates. The main features of this variation are the following :

1) In the region of slight etch (i.e. for a decrement in thickness, $\Delta d_{\mathrm{s}}$, smaller than $4 \mu \mathrm{m}$ ) we observe a rapid increase in the $Q$-factor which can be understood in terms of the progressive etching of the disturbed surface layer which is created by the mechanical lapping and whose depth can be estimated to be about $2 \mu \mathrm{m}$ [11].

2) In the medium region (i.e. for depth of etch $\Delta d_{\mathrm{s}}$ in the range $\left.2 \mu \mathrm{m}-12 \mu \mathrm{m}\right)$ the $Q v s . \Delta d_{\mathrm{s}}$ plot presents a flat maximum $Q_{\max }$. It has been found that the BT-49 surfaces are covered by dissolution figures governed by orientation effects and the correspond- 

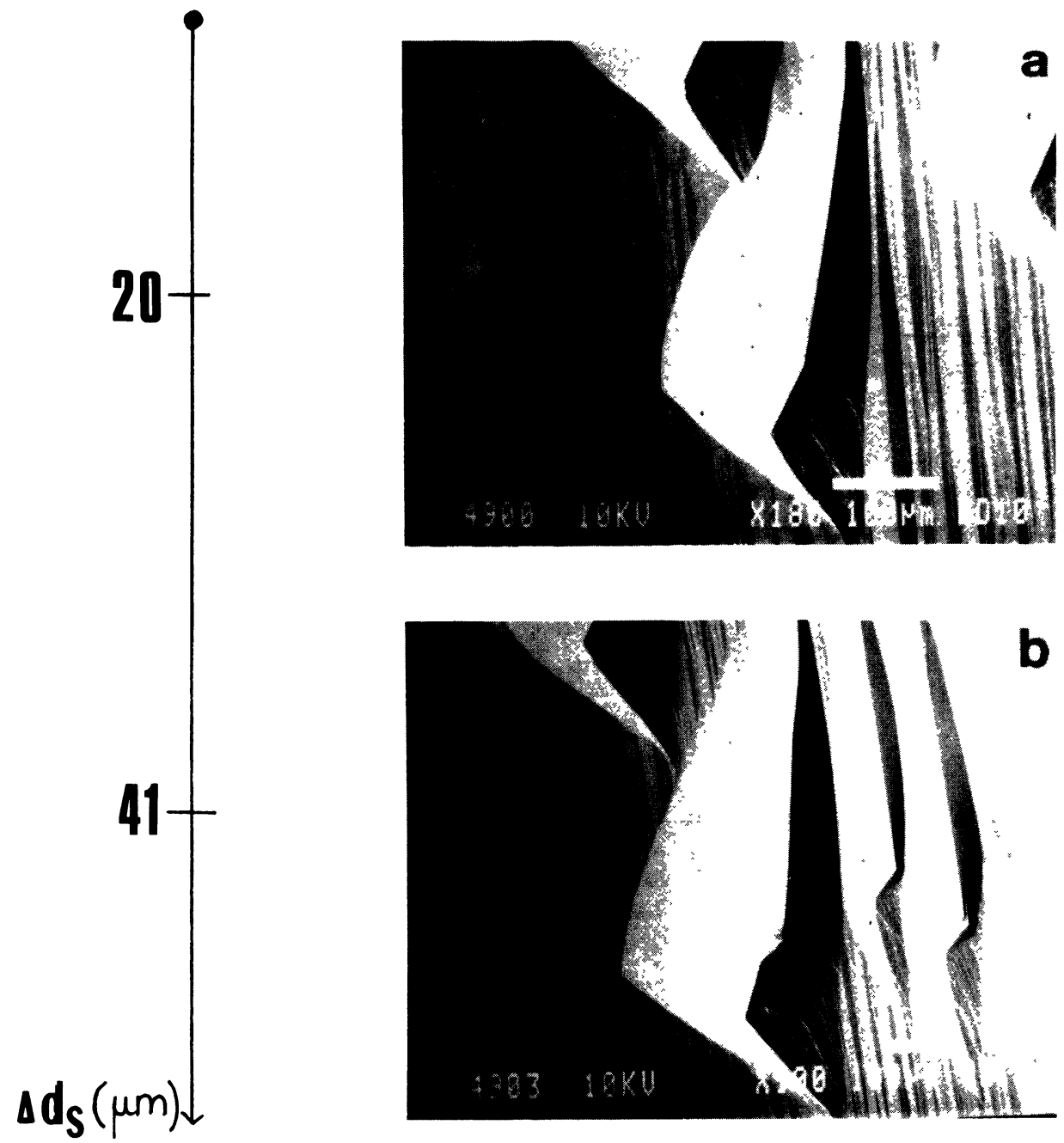

Fig. 7. - Formation of etch pits in the last stages of etching : a) $\Delta d_{\mathrm{s}} \simeq 20 \mu \mathrm{m}$; b) $\Delta d_{\mathrm{s}} \simeq 41 \mu \mathrm{m}$.

ing $R_{\mathrm{q}}$ and $R_{\max }$ parameters do not markedly change on dissolution. Hence the relative independence of the $Q$-factor on the depth of etch in the medium region can be explained by quasi independent average values $R_{\max }$ and $R_{\mathrm{q}}$ equal to $2.5 \mu \mathrm{m}$ and $0.25 \mu \mathrm{m}$ respectively. (The size of the dissolution figure is varying, but its depth is remaining quasi constant).

3) In the region of deep etch (i.e. for $\Delta d_{\mathrm{s}}$ in the range $17 \mu \mathrm{m}-42 \mu \mathrm{m})$ the $Q$ factor falls rapidly to very low values (typically 23000 ). This rapid decrease in $Q$ can be understood in terms of the development of deep and large dislocation etch pits with continuously varying size and depth.

\section{Discussion and conclusion.}

Turning to the theoretical formulation of the reflection coefficient for rough surfaces it should be pointed out that we can deal with a reflection coefficient only if the roughness of the surface does not include sharp edges or irregularities with small radii of curvature [15]. In other words equation (20) remains valid until the parameters $a$ and $b$ of dissolution figures or etch pits are large compared with the wavelength of the acoustical wave.

For the resonators into consideration here the above requirement is crudely fulfilled by the dislocation etch pits which act as diffracting objects of large size. Hence in practice we can reasonably expect that the present model explains quite accurately the behaviour of deeply etched quartz resonators.

\subsection{A DESCRIPTION FOR THE TEXTURE OF DEEPLY} ETCHED BT-49 PLATES. - In the region of deep etching surface texture studies have shown it is convenient to classify the etch pits by their depth i.e. by their $R_{\max }$ parameter. Then we have to evaluate numerically the r.m.s. roughness, $R_{\mathrm{q}}$ associated with the maximum peak-to-valley height, $R_{\max }$, of a given category of etch pits. For this purpose we have made, at various etching times, profilometry traces on differently oriented quartz plates. These traces exhibit different geometrical shapes and maximum 

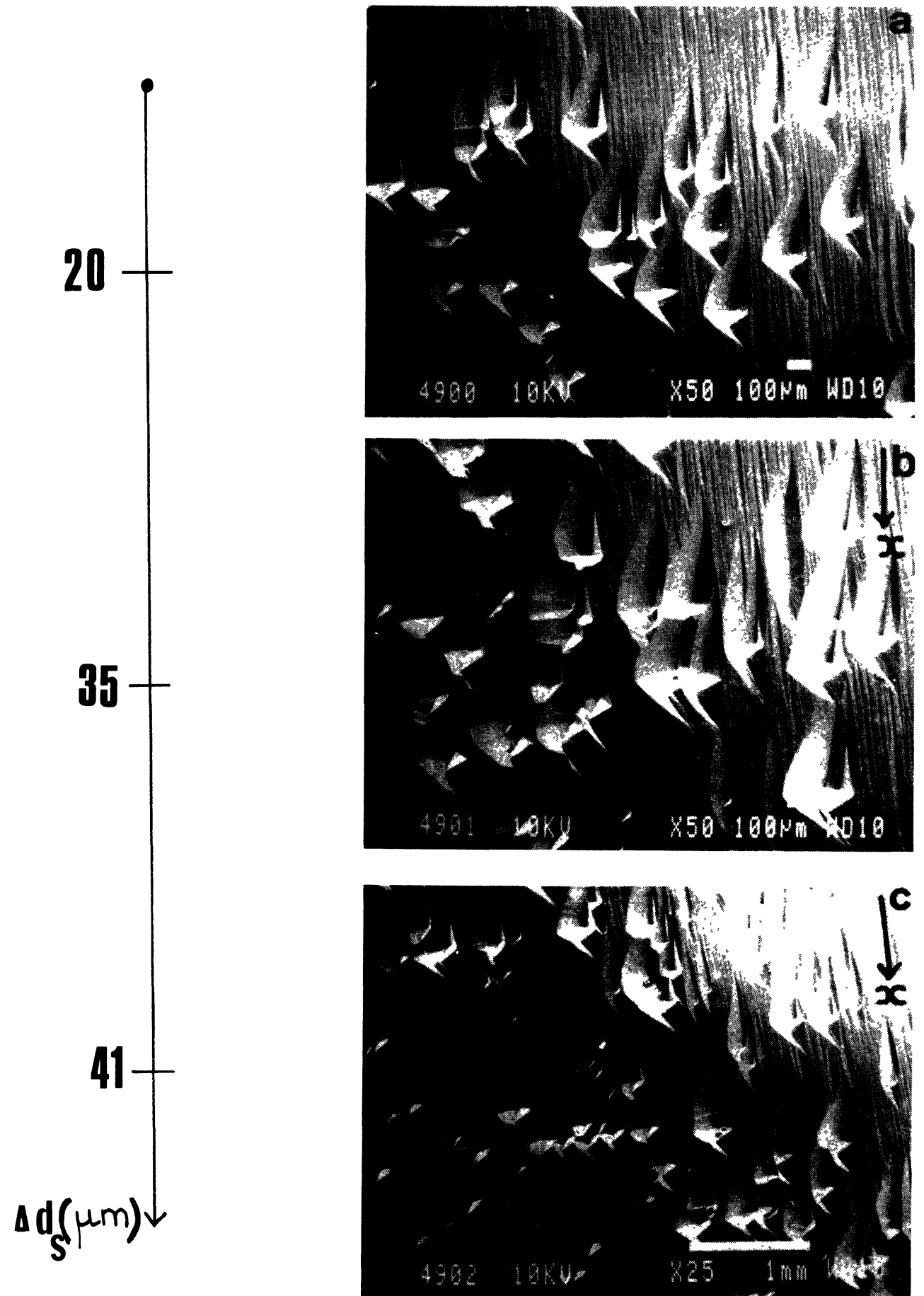

Fig. 8. - Evolution of the density of etch pits with the depth of etch $\Delta d_{\mathrm{s}}$ : a) $\Delta d_{\mathrm{s}} \simeq 20 \mu \mathrm{m}$; b) $\Delta d_{\mathrm{s}} \simeq 25 \mu \mathrm{m}$; c) $\Delta d_{\mathrm{s}} \simeq 35 \mu \mathrm{m}$

peak-to-valley heights. In calculating the r.m.s. roughness we have to choose a meter cut-off in order to isolate the roughness [19]. Here the values of $R_{\mathrm{q}}$ are calculated by using a long meter cut-off. In this condition we can reasonably suppose that the value of $R_{\mathrm{q}}$ is essentially determined by the deeper geometrical defect corresponding to the maximum peak-to-valley height, $R_{\max }$. Drawing the variation of $R_{\mathrm{q}}$ with $R_{\max }$ gives the mean curve illustrated in figure 11. According to the classification of dislocation etch pits, the description of deeply etched BT49 surfaces is achieved by connecting the distribution of etch pits with respect to their depth i.e. to their $R_{\max }$ range of values with the fraction $s_{\mathrm{E}}$ of the surface area corresponding to pits whose depth reaches at least $-R_{\max 1}$ (Fig. 12). The amount of experimental data is sufficient to estimate $s_{\mathrm{E}}$ with a relatively good accuracy $(5 \%)$ provided the density 

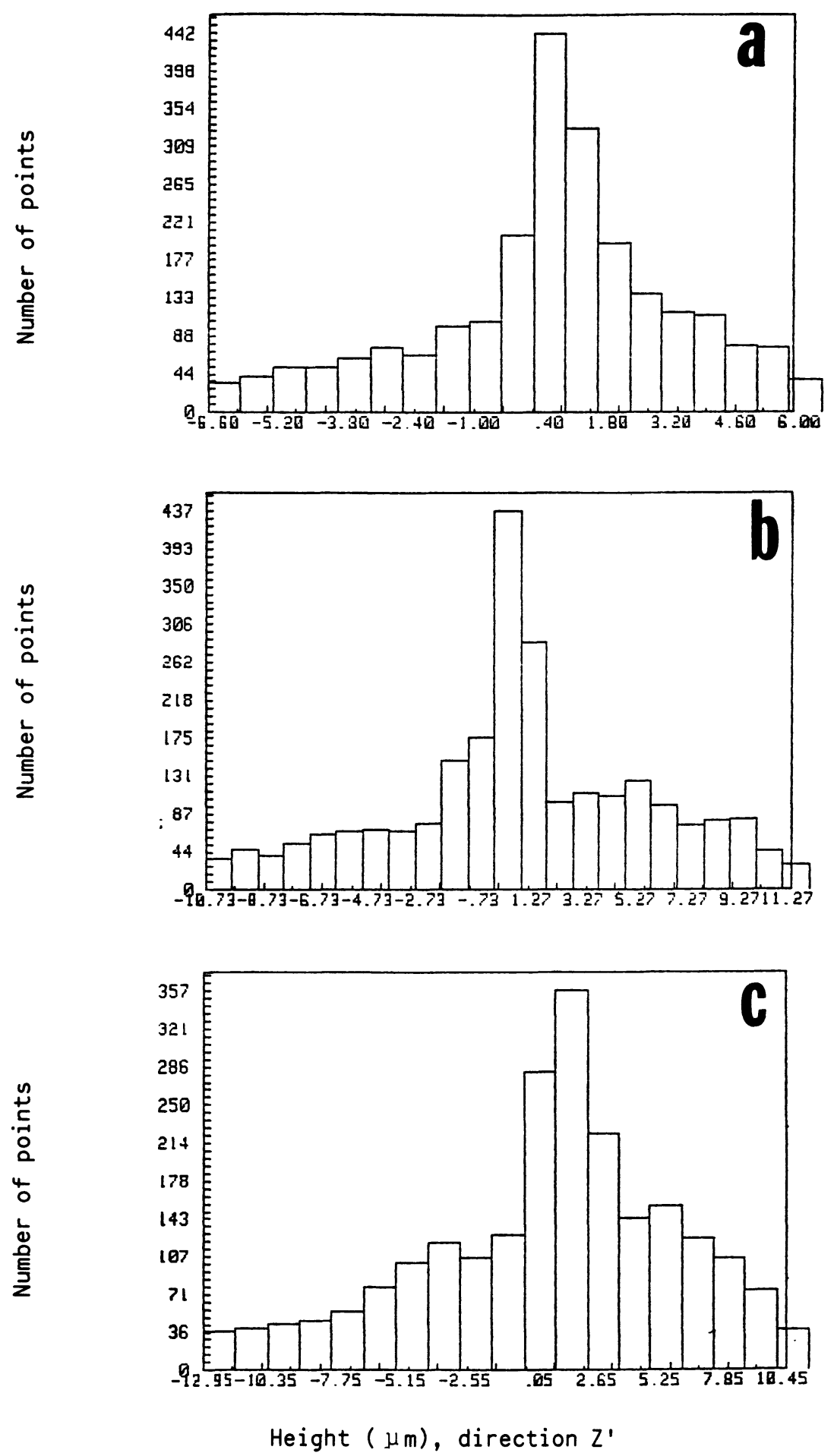

Fig. 9. - Evolution of the distribution of heights with the depth of etch, $\Delta d_{\mathrm{s}}$ : a) $\Delta d_{\mathrm{s}} \simeq 25 \mu \mathrm{m}$; b) $\Delta d_{\mathrm{s}} \simeq 35 \mu \mathrm{m}$; c) $\Delta d_{\mathrm{s}} \simeq 41 \mu \mathrm{m}$.

of dislocation etch pits is not too low. Finally we assign to each category of etch pits a single $R_{\mathrm{q}}$ value which is that given by the $R_{\mathrm{q}} v s$. $R_{\max }$ plot assuming that for this category of pits whose depths lie within $-R_{\max 1}$ and $-R_{\max 2}$ the roughness arises principally from deeper pits characterized by $R_{\max 2}$. It is obvious that with this procedure the action of the dislocation etch pits upon the $Q$-factor will be overestimated.

4.2 ANALYSIS OF DATA ON $Q$ FACTOR. - We have to determine the $Q$-factor, $Q_{\mathrm{F}}^{*}$, of a deeply etched resonator with a surface exhibiting different categories of etch pits. 


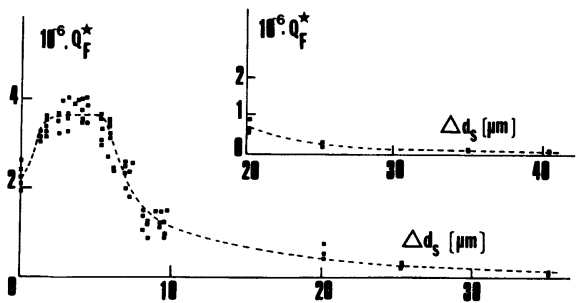

Fig. 10. - Variations of the $Q$-factor with the depth of etch, $\Delta d_{s}$, of BT-49 plates.

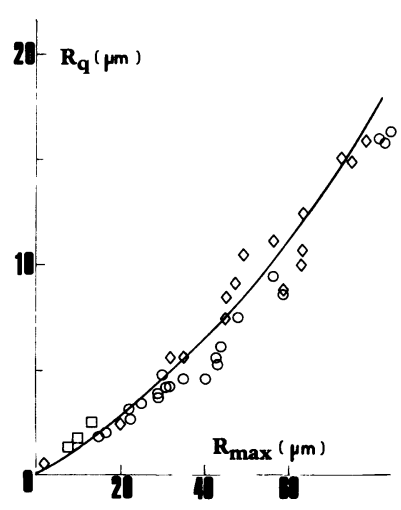

Fig. 11. - Variations of the r.m.s. roughness, $R_{\mathrm{q}}$, with the geometrical parameter $R_{\max }$.

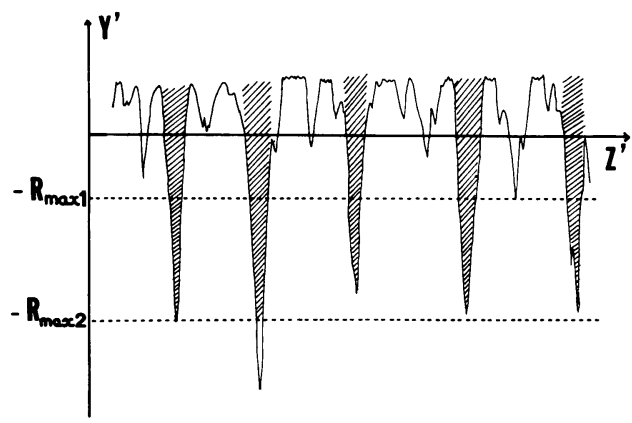

Fig. 12. - Definition of a category $i$ of pits whose depths lie in the range $\left(-R_{\max 1},-R_{\max 2}\right)$.

For this purpose an attempt is made to estimate the $Q$-factor $Q_{\mathrm{F}}$ of a resonator with rough surfaces covered in the one hand by dissolution figures and the second hand by a given category of dislocation etch pits.

Let us denote $Q_{\mathrm{D}}$ and $Q_{\mathrm{E}}$ the $Q$ factors related to an etched quartz surface covered entirely by dissolution figures and dislocation etch pits respectively. $Q_{\mathrm{D}}$ is readily identified with the maximum $Q_{\max }$, of the $Q v s . \Delta d_{\text {s }}$ plot. Consider now a deep etching which results in the formation of dislocation etch pits ranging in a single category on a fraction $s_{\mathrm{E}}$ of the total surface of the resonator ; the dissolution figures being uniformly arranged on the rest of the quartz surface, i.e. on fraction $s_{\mathrm{D}}=1-s_{\mathrm{E}}$ of the total surface. We want to express the $Q$-factor, $\mathrm{Q}_{\mathrm{F}}$, of the resonator which accounts for the simultaneous diffraction of acoustical waves on the dissolution figures and etch pits in terms of measurable physical quantities, namely $Q_{\mathrm{D}}, Q_{\mathrm{E}}, s_{\mathrm{E}}$ and $s_{\mathrm{D}}$.

The resulting $Q^{-1}$ is generally written $[1,4,8]$ as the sum of the $Q_{\mathrm{r}}^{-1}$ due to various independent loss mechanisms of type « $\mathrm{r}$ » (for example : mounting, contamination, intrinsic losses within the crystal, etc.) $[1,4]$. Hence, in the present case, a possible formulation for $Q_{\mathrm{F}}^{-1}$ taking into account the surface losses through dissolution figures and etch pits of only one category is :

$$
\begin{aligned}
Q_{\mathrm{F}}^{-1}= & Q_{\mathrm{D}}^{-1}\left[\nu_{0}+\nu_{1} s_{\mathrm{D}}+\nu_{2} s_{\mathrm{D}}^{2}+\nu_{3} s_{\mathrm{D}}^{3}+\cdots\right]+ \\
& +Q_{\mathrm{E}}^{-1}\left[\varepsilon_{0}+\varepsilon_{1} s_{\mathrm{E}}+\varepsilon_{2} s_{\mathrm{E}}^{2}+\varepsilon_{3} s_{\mathrm{E}}^{3}+\cdots\right]
\end{aligned}
$$

which may be expressed in the form of a polynomial expansion of $s_{\mathrm{E}}$, limited to the $m$-th degree for practical use

$$
Q_{\mathrm{F}}^{-1}=\sum_{p=0}^{m}\left(\nu_{p}^{*} Q_{\mathrm{D}}^{-1}+\varepsilon_{p} Q_{\mathrm{E}}^{-1}\right) s_{\mathrm{E}}^{p}
$$

In the preceding polynomial regression it must be kept in mind that $Q_{\mathrm{D}}$ includes the loss mechanisms attributed to mounting, contamination and so on. The final formula is reasonably simple and seems plausible but prompts us to determine experimentally the unknowns coefficients $\nu_{p}^{*}$ and $\varepsilon_{p}$.

Equation (27) does not contain any restriction on the values of $Q_{\mathrm{D}}$ and $Q_{\mathrm{E}}$. Therefore equation (27) holds also for quartz surfaces composed of distinct regions produced by various mechanical processes such as lapping and polishing. Starting from optically polished quartz resonators with an initial $Q$-factor, $Q_{\text {polished }}=\mathrm{Q}_{\mathrm{D}}$, we have damaged by successive lappings an increasing fraction of the polished surfaces to obtain in the final step resonators with entirely lapped surfaces which have a final $Q$-factor, $Q_{\text {lapped }}=Q_{\mathrm{E}}$. Repeating this procedure on differently oriented quartz plates in order to deal with resonators presenting different values for the initial and final $Q$ factors, it is possible to evaluate the constants $\nu_{p}^{*}$ and $\varepsilon_{p}$ appearing in equation (28). Theoretical variations of the ratio $Q_{\mathrm{D}} / Q_{\mathrm{F}}$, with the fraction $s_{\mathrm{E}}$ of the rougher surface area computed from equation (27) are shown in figure 13 for different values of $Q_{\mathrm{E}}$ (i.e. for different geometrical defects described by different $R_{\mathrm{q}}$ values. If the density of rougher pits tends to a zero value (i.e. in the limit $s_{\mathrm{E}} \rightarrow 0$ ) some difficulties arise in the procedure of identification for the constants $\nu_{p}^{*}$ and $\varepsilon_{p}$ and it appears that the predicted changes in $Q_{\mathrm{F}}$ with $s_{\mathrm{E}}$ are not so good for $s_{\mathrm{E}}<0.15$. These difficulties may be attributed to a lack of experimental data in the range $0<s_{\mathrm{E}}<0.25$, but it should be remarked that, in this case, preparing partly lapped quartz together with controlling precisely the area of 


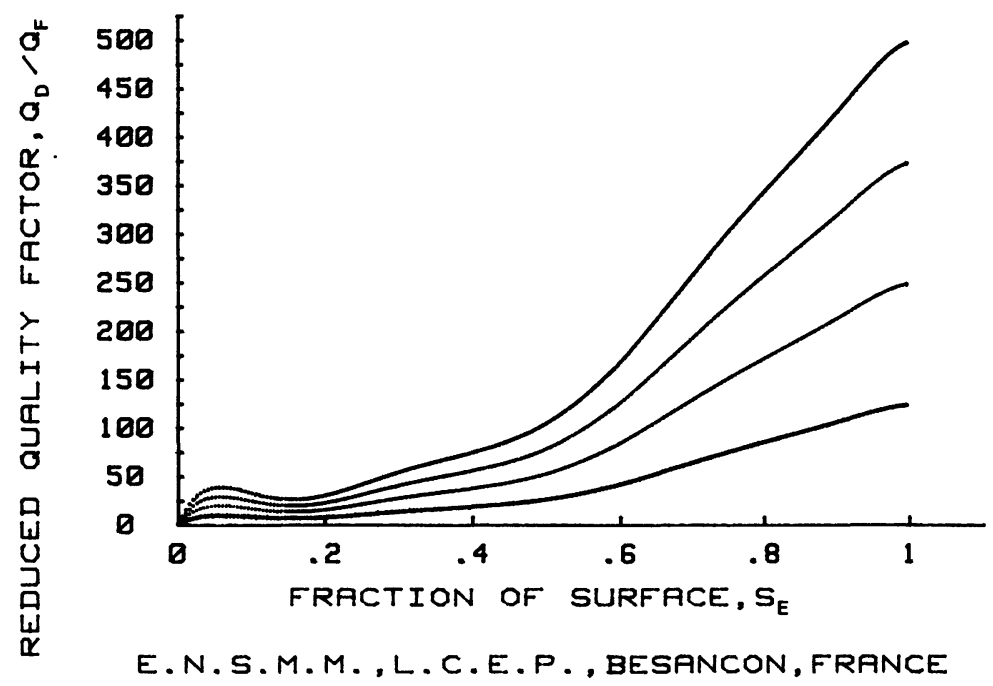

Fig. 13. - Theoretical variations of the $Q$-factor ratio, $Q_{\mathrm{D}} / Q_{\mathrm{F}}$, with the fraction $s_{\mathrm{E}}$ of the rougher surface area.

the lapped regions and with verifying that the lapping process does not generate a damaged surface layer remains a very difficult task. Then it seems reasonable to assume that the curves of figure 13 represent quite accurately the variations of $Q_{\mathrm{F}}$ with $s_{\mathrm{E}}$ can be crudely described by the exponential law of the form :

$$
Q_{\mathrm{F}}=Q_{1} \exp \left\{g s_{\mathrm{E}}\right\}
$$

where we have to consider the limiting conditions to estimate the constants $Q_{1}$ and $g$.

As stated in 4.1 , the surface of a deeply etched quartz resonator is covered by etch pits of several categories. At this stage of analysis, a convenient method to predict the quality factor of deeply etched quartz resonators is the following :

1) determine the fractions of area, $s_{\mathrm{E}_{j}}$, corresponding to the various categories $j$ of etch pits with sizes $a_{j}$ and $b_{j}$ which develop on deeply etched plates ;

2) evaluate the roughness $R_{\mathrm{q}_{j}}$ associated with each category of etch pits through the $R_{\mathrm{q}} v s . R_{\max }$ plot;

3) deduce from the present theoretical model the $Q$-factor, $Q_{\mathrm{E}_{j}}$ related to an uniformly rough surface with given values of the parameters, $a_{j}, b_{j}$ and $R_{\mathrm{q}_{j}}$;

4) estimate the $Q$-factor, $Q_{\mathrm{F}_{j}}^{*}$, associated with each category, $j$, of dislocation etch pits ;

5) for a given etched quartz plate define two limiting values $Q_{\mathrm{Fm}}$ and $Q_{\mathrm{FM}}$, of the final $Q$-factor, $Q_{\mathrm{F}}$, by means of the formulaes :

$$
\begin{gathered}
Q_{\mathrm{FM}}=\operatorname{minimum}\left(Q_{\mathrm{F}_{j}}\right) \\
Q_{\mathrm{Fm}}^{-1}=\sum_{j} Q_{\mathrm{F}_{j}}^{-1} .
\end{gathered}
$$

In view of the complexity of geometrical features exhibited by deeply etched plates it is unreasonable to propose a theoretical value for the final $Q$-factor, but it is now possible to determine in what range lies the final $Q$-factor. Effectively, $Q_{\mathrm{F}}^{*}$ cannot exceed $Q_{\mathrm{FM}}$ and cannot take values lower than that corresponding to $Q_{\mathrm{Fm}}$. It may be remarked that by writing equation (31) we have again necessarily overestimated the influence of the various categories of etch pits on the final $Q$-factor.

In order to assess the validity of the present model an attempt to fit experimental data related to deeply etched BT-49 resonators by following this rather complicated procedure is shown in figure 14. In the deep etching region most of the experimental data are located on the theoretical bars representing the expected range of values for $Q_{\mathrm{F}}^{*}$. This demonstrates that the proposed model describes quite accurately the diffraction at deeper pits.

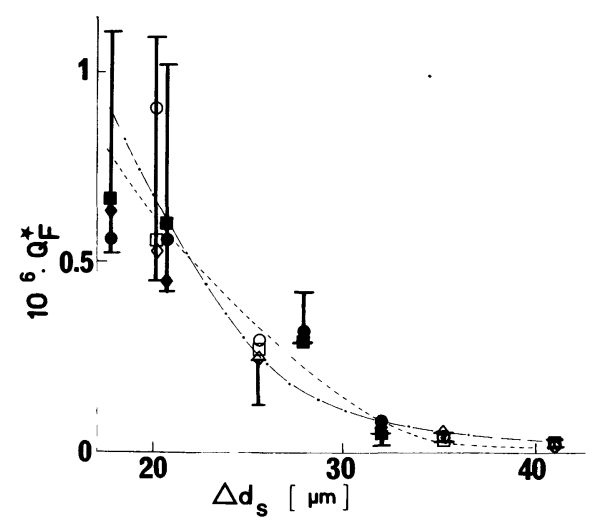

Fig. 14. - Theoretical bars corresponding to the two limiting values of the final $Q$-factor. Curves A and B correspond respectively to BT-41 $(\bullet, \diamond, \square)$ and BT-49 (O, $\diamond, \square)$ plates. 
Departures from the theory can occur because it is not easy to adjust the average of $a_{j}, b_{j}$ and $R_{\max j}$ measurements when the dislocation etch pits are not uniformly distributed on the etched surfaces and because the procedure of analysis tends to enhance the influence of the dislocation etch pits.

Hence to confirm the validity of the present model the final $Q$-factor of deeply etched BT- 41 resonators is also plotted (Fig. 14) as a function of the depth of etch. Effectively on etching the BT-41 surfaces behave as the BT-49 surface : the essential feature which is the development of deep dislocation etch pits of large width is again observed even if the shape of etch pits differs from one type of surfaces to another. Moreover for deeply etched BT-41 plates the density of dislocation etch pits is found to vary rapidly with the depth of etch ; then, the separation of etch pits into different categories is still justified. The results shown in figure 14 undoubtedly indicate a rapid fall of $Q_{\mathrm{F}}^{*}$ with $\Delta d_{\mathrm{s}}$ in agreement with the predicted changes of $Q_{\mathrm{F}}^{*}$. From that we can infer that as far large pits occur the present model is proved very successful in describing the additional attenuation due to the scattering by very rough surfaces.

\section{References}

[1] Vigoureux P. and Booth C. F., Quartz Vibrators and their Applications (His Majesty's Stationery Office, London) 1950, Chap. 7.

[2] Fukuyo H., Oura N., Kitajima N. and Kono H., J. Appl. Phys. 50 (1979) 3653.

[3] Fukuyo H. and Oura N., Proc. of the 30th Annual Symposium on Frequency Control, Fort Monmouth, New Jersey, 1976 (Electronic Industries Association, Washington, DC) 1976, p. 254.

[4] Vig J. R., BRandmayR R. J. and Filler R. L. Report $n^{\circ}$ DELET-TR 80-5 (US Army Electronics Research and Development Command, Fort Monmouth, New Jersey) 1980.

[5] Brandmayr R. J. and VIG J. R., Report $n^{\circ}$ DELET-TR-81-16 (US Army Electronics Research and Development Command, Fort Monmouth, New Jersey) 1981.

[6] Vig J. R., Cook C. F., Schwidtal K., Lebus J. W. and HAFNer E., Proc. of the 28th Annual Symposium on Frequency Control, Fort Monmouth, New Jersey, 1974 (Electronic Industries Association, Washington, D.C.) 1974, p. 96.

[7] JONES K. H., Proc. of the 41st Annual Symposium on Frequency Control, Philadelphia, Pa, 1987 (I.E.E.E., New York), 1987, p. 199.

[8] Castellano R. N. Meeker T. R., Sundahl R. C. and JACOBS J. C., Proc. of the 31st Annual Symposium on Frequency Control, Atlantic City, U.S.A., 1977 (Electronic Industries Association, Washington, D.C.) 1977, p. 126.

[9] Sekigughi Y. and Funakubo H., J. Mater. Sci. 15 (1980) 3066.

[10] Tellier C. R., Surf. Technol. 21 (1984) 83.

[11] Tellier C. R. and Buron C., Surf. Technol. 22 (1984) 287.

[12] Castagliola M., Tellier C. R. and Vaterkowski J. L., J. Mater. Sci. 21 (1986) 3551.

[13] Tellier C. R. and Jouffroy F., J. Mater. Sci. 18 (1983) 3621.
[14] Auld B. A., Acoustic Fields and Waves in Solids (John Wiley, New York) 1973.

[15] Beckmann P. and Spizzichino A., The Scattering of Electromagnetic waves from Rough Surfaces (Pergamon Press, London) 1963.

[16] Born M. and Wolf E., Principles of Optics (Pergamon Press, Oxford), 1965.

[17] Sмiтн B. C., I.E.E.E. Trans. Antennas Propag. AP15 (1967) 668

[18] Beckmann P., I.E.E.E. Trans. Antennas Propag. AP-13 (1965) 384.

[19] Ed. T. R. Thomas, Rough Surfaces (Longman, London) 1981, Chap. 4.

[20] Deguin-Leblois T. and Bourouin R., Proc. of the 1st European Time and Frequency Forum, Besançon, France, 1987 (Imprimerie du Conseil Général du Doubs) 1987, p. 184.

[21] Leblois T., Bourquin R. and Tellier C. R., Proc. of the 2nd European Time and Frequency Forum, Neuchâtel, Switzerland, 1988 (Fondation Suisse pour la Recherche en Microtechnique) 1988 , p. 893.

[22] Dieulesaint E. and Royer D., Ondes Elastiques dans les Solides (Masson, Paris) 1974.

[23] Wegner M. W. and Christie J. M., Phys. Chem. Minerals 9 (1983) 67.

[24] Tellier C. R., Proc. of the 2nd European Time and Frequency Forum, Neuchâtel, Switzerland, 1988. (Fondation Suisse pour la Recherche en Microtechnique) 1988 , p. 937.

[25] SANGWAL K., Etching of Crystals (North-Holland, Amsterdam) 1987, chap. 11.

[26] Heimann R. B., Silicon Chemical Etching, Ed. J. Grabmaier (Springer, Berlin) 1982, pp. 197-207.

[27] Tellier C. R., Vialle N. and Vaterkowski J. L., Surf. Coatings Technol. 34 (1988) 417.

[28] Tellier C. R. and VAterkowski J. L., J. Mater. Sci. (1988) to be published.

[29] IRving B. A., The Electrochemistry of Semiconductors, Ed. P. J. Holmes (Academic Press, London) 1962 , pp. 256-89. 